\title{
Theorising the Open curriculum as pathway to Responsiveness to in South African higher education
}

\author{
George Fomunyam Kehdinga \\ Mangosuthu University of Technology
}

\begin{abstract}
.
Curriculum discourse in South African higher education has always involved debates around responsiveness and how to best make the curriculum respond to local needs. This was amongst the reasons for the call to decolonise the curriculum. With encounters in education being a function of the curriculum at play, it follows that the curriculum shapes the educational experience and how prepared students are for the job market be it to create employment or to seek one. With the rate of unemployment in South Africa increasing on the rise, the nation needs graduates who are job creators not job seekers. The open curriculum offers an excellent pathway for educational encounters which are not only responsive but uniquely career oriented.

This paper adopts Aoki's conceptualisation of the curriculum as lived experience and make three fundamental arguments. Firstly, the paper argues that there is need for the deconstruction of academic curriculum standardisation. Secondly the paper argues for an itinerant curriculum and lastly, the paper argues for curriculum encounters propelled by responsive curriculum matters in the South African higher education. The paper concludes that career pathways have been hindered by poor curriculum choices which itself has been engendered by curriculum standardisation and hegemonic curriculum practices which adopts a one size fits all approach. For higher education curriculum to be responsive students as co-constructors or creators of knowledge need to be path of the process and drive the change they want to see in their future.
\end{abstract}

Keywords: open curriculum, responsiveness, higher education, students, experiences 